\title{
Synthesis and Characterization of Zeolitic Material Derived from Sugarcane Straw Ash
}

\author{
Denise A. Fungaro ${ }^{1, *}$, Thais V. S. Reis ${ }^{1}$, Marco Antonio Logli ${ }^{2}$, Nara A. Oliveira ${ }^{2}$ \\ ${ }^{1}$ Instituto de Pesquisas Energéticas e Nucleares, IPEN-CNEN/SP, São Paulo ,Brasil \\ ${ }^{2}$ Centro de Pós-Graduação “Oswaldo Cruz”, São Paulo-SP- Brasil \\ *Corresponding author: dfungaro@ipen.br
}

Received January 20, 2014; Revised February 22, 2014; Accepted February 27, 2014

\begin{abstract}
Sugarcane straw ash (SCSA), an agricultural waste of sugar industry with disposal problems, was utilized as a source for the synthesis of zeolitic material. Zeolitic material was synthesized by alkali fusion followed by hydrothermal treatment. The effect of crystallization time was studied and the conditions optimized. The materials were characterized by XRD, XRF, SEM, FT-IR, Brunauer-Emmett-Teller (BET) surface area techniques, particle size analyzer, TG /DSC and nitrogen physisorption. The presence of zeolite NaP1 in adsorbent confirms successful conversion of native SCSA into zeolitic material. The physico-chemical properties of SCSA and zeolitic material were compared. The particle size distribution of zeolitic material was in the range of $0.796-399 \mu \mathrm{m}$ and nitrogen adsorption indicated a surface area around $350 \mathrm{~m}^{2} \mathrm{~g}^{-1}$. Zeolitic material from sugarcane straw ash was examined by removal of Crystal violet from aqueous solution.
\end{abstract}

Keywords: biomass ash, sugarcane straw, zeolite, fusion method

Cite This Article: Denise A. Fungaro, Thais V. S. Reis, Marco Antonio Logli, and Nara A. Oliveira, "Synthesis and Characterization of Zeolitic Material Derived from Sugarcane Straw Ash." American Journal of Environmental Protection, vol. 2, no. 1 (2014): 16-21. doi: 10.12691/env-2-1-4.

\section{Introduction}

Sugarcane is used worldwide as a feedstock for ethanol and sugar production. Brazil is the largest producer of sugarcane of the world generating 400 million tons per year, on average. According to the Brazilian National Food Supply Company, in the 2010/2011 season, 8 million ha was used to produce sugar cane, producing 624 million tons [1].

Sugarcane processing to produce sugar and ethanol generates several agricultural residues, being straw and bagasse is considered as the main among them. An amount of 1 ton of sugarcane generates 270kg bagasse and $144 \mathrm{~kg}$ trash/straw [2].

Sugarcane straw is the material that is removed before the cane is crushed and comprises the dried/fresh leaves and the top of the plant [3,4].

The crop of sugarcane is initiated with the burn of sugarcane straw "in situ", on a controlled way, in small and delimited areas. The amount of ashes generated in the process represents $3 \%-5 \%$ of the initial residues, which constitutes a considerable volume of ashes. Studies showed that part of the population - especially the elderly, children and asthmatics - suffers health effects caused by sugarcane burning in Brazil [5,6,7].

The sugarcane industry is seeking solutions to dispose of the wastes generated by the sugar and alcohol production processes. So, the recycling of industrial wastes from the agriculture sector is increasingly encouraged.
Agricultural residues are normally composed of organic constituents such as cellulose, lignin, fibers and small amounts of crude protein and fat. In addition, they contain a range of minerals, which include silica, alumina and iron oxides.

It was already known that sugarcane straw ashes (SCSA) can be recycled in the manufacture of commercial cements and other composites, as pozzolanic material $[8,9,10]$.

One possibility for effective usage of those wastes is to convert the SCSA into zeolites for environmental uses. Sugarcane straw ashes contains aluminosilicates glass, mullite and quartz, which are the required building blocks of zeolite formation $[8,9,10]$.

The synthesized zeolites are used in various applications, such as adsorbent material, catalysts, gas and hydrocarbon separators and waste encapsulation. In our group we have been developing zeolites synthesized from Brazilian coal fly ashes $[11,12,13,14]$. Some authors have reported the conversion of bagasse fly ash into zeolites $[15,16,17,18]$, but apart from one earlier study, are no reports on the conversion of sugarcane straw ash into zeolites.

This research aims to find the optimal conditions to generate zeolite from SCSA by fusion method using $\mathrm{NaOH}$ as the activation reagent. The influences of reaction condition, such as hydrothermal temperature on the products were investigated to optimize the synthesis. The SCSA and obtained zeolites were also characterized by chemical composition and phase analysis, particle size analysis, thermal analysis, and morphological. The 
potential of synthesized zeolitic material for capturing crystal violet dye in water was also examined.

\section{Experimental}

\subsection{Materials}

All the regents used were of analytical grade. The sugarcane straw was collected in Piracicaba city located at state of São Paulo, Brazil. This waste was gathered as dry straw, it was cut in order to obtain fibres between 20 and $30 \mathrm{~mm}$ long and the material was ground by oscillating mill. Sugarcane straw ashes (SCSA) from the combustion of sugarcane straw were obtained in a muffle furnace at $700^{\circ} \mathrm{C}$ during $20 \mathrm{~min}$.

\subsection{Zeolite Synthesis}

The SCSA was converted to zeolite using the fusion method. The method started with mixing SCSA with ground $\mathrm{NaOH}$ anhydrous pellet at a weight ratio of 1:1.3. The homogeneous mixture was then calcined in $550^{\circ} \mathrm{C}$ for $1 \mathrm{~h}$. The fusion products were ground and poured into a plastic bottle followed by the addition of distilled water and mixed in a shaking machine at room temperature for $24 \mathrm{~h}$. The resulting slurry was then subjected to crystallization at $100^{\circ} \mathrm{C}$ by varying the reaction time (6, 24 and $45 \mathrm{~h}$ ). The solid product was separated from the solution using filtration and then washed with distilled water until the $\mathrm{pH}$ of solution was down to $10-11$ and then dried overnight (about $12 \mathrm{~h}$ ) at $50^{\circ} \mathrm{C}$. The synthesis products were named as SCSA-6, SCSA-24 and SCSA-45.

\subsection{Characterization of Materials}

The chemical compositions of materials in the form of oxides were analyzed by energy dispersive XRFX-ray fluorescence spectrometry (RX Axios Advanced, PANalytical, Phillips spectrometer). Phase and crystallinity were confirmed by powder XRD (Rigaku Multiflex) with nickel filter $\mathrm{CuK} \alpha$ radiation $(\lambda=1.54060$ A) scanning from 5 to $80^{\circ}$ at a rate of $1 \%$ min with current $40 \mathrm{kV}$ and $20 \mathrm{~mA}$. The Fourier transform infrared spectroscopy (FTIR) spectra were recorded on Nexus 670 Thermo Nicolet using $\mathrm{KBr}$ pellet method. Scanning Electron micrograph was obtained by using XL-30 Philips scanning electron microscope (SEM). The particle size of the materials was measured using a laser based particle size analyzer, namely a Malvern MSS Mastersizer 2000 Ver. 5.54. Adsorption isotherms were measured with Micromeritics TriStar volumetric adsorption analyser using nitrogen of $99.999 \%$ purity. Measurements were performed in range of relative pressure from $10^{-6} 0.99$ liquid nitrogen on the samples degased for $2 \mathrm{~h}$, under vacuum about $50 \mathrm{mTorr}$, at $200^{\circ} \mathrm{C}$. The specific surface area was evaluated using BET method. The total pore volume was estimated from the amount adsorbed at the relative pressure of 0.99 . The pore size distribution (PSD) was calculating using BLH algorithm with the relation between the capillarity condensation pressure and the pore diameter [19]. Thermogravimetry (TG) and Diferential Scaning Calorimetry (DSC) curves were obtained on a model Q600 SDT Analyser (TA Instruments) using a sample mass of around $19 \mathrm{mg}$ in Pt crucible, heating rate of 5 or $10^{\circ} \mathrm{C} \min ^{-1}$ up to $1000^{\circ} \mathrm{C}$ under dynamic nitrogen atmosphere $\left(100 \mathrm{~mL} \mathrm{~min}^{-1}\right)$.

\subsection{Adsorption of Crystal Violet Dye}

Crystal Violet (CV) was purchased from ProtonResearch and considered as purity $100 \%$. The adsorption was performed using the batch procedure. Kinetic experiments were carried out by agitating $0.1 \mathrm{~g}$ of adsorbent with $10 \mathrm{~mL}$ of dye solution at room temperature $\left(25^{\circ} \mathrm{C} \pm 2^{\circ} \mathrm{C}\right)$ at $120 \mathrm{rpm}$ for $24 \mathrm{~h}$. The collected samples were then centrifuged (3000 rpm during $30 \mathrm{~min}$ ) and the concentration in the supernatant solution was analyzed using a UV spectrophotometer (Cary 1E, Varian) by measuring absorbance at $\lambda=590 \mathrm{~nm}$ and $\mathrm{pH}=5$.

\section{Results and Discussion}

\subsection{Characterization of Materials}

\subsubsection{Powder X-ray DiffractionAnalysis}

XRD patterns of the untreated (SCSA) and thermally treated sugarcane straw ashes (SCSA-6, SCSA-24 and SCSA-45) are shown in Figure 1 and Figure 2, respectively. The identification and interpretation of PXRD patterns of the materials are prepared by comparing the diffraction database provided by "International Centre for Diffraction Data / Joint Committee on Power Diffraction Standards” (ICDD/JCPDS).

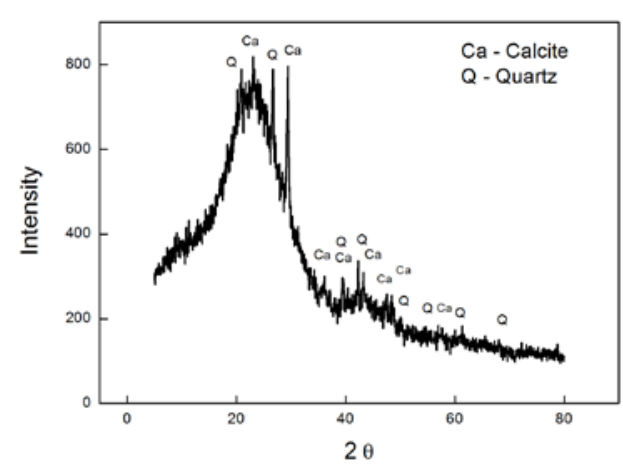

Figure 1. XRD patterns of sugarcane straw ash

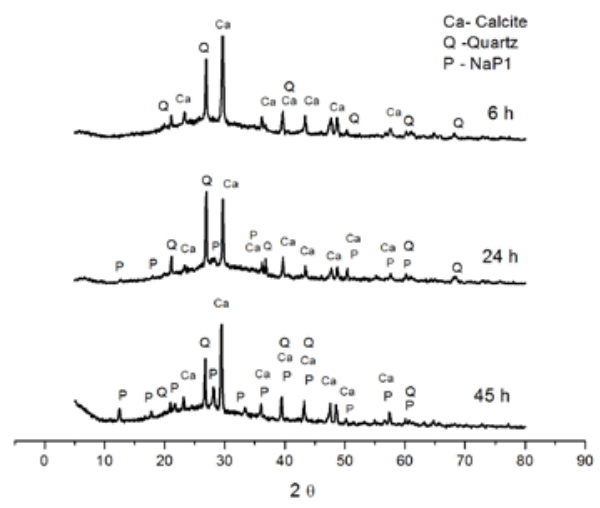

Figure 2. XRD patterns of the synthesis products obtained by hydrothermal treatment of sugarcane straw ash for 6,24 and $45 \mathrm{~h}$ (SCSA-6, SCSA-24 and SCSA-45) 
SCSA shows a very low crystallinity and wide band is observed between 10 and 30 (2-theta), which implies the presence of vitreous matter. Moreover, the XRD patterns suggest the presence of calcite $\left(\mathrm{CaCO}_{3}\right.$, ICDD/JCPDS 01071-3699) as the main crystalline compound with quartz ( $\mathrm{SiO}_{2}, \mathrm{ICDD} / \mathrm{JCPDS}$ 001-0649) as minor compounds.

The amorphous aluminosilicate nature of SCSA makes its chemical composition difficult to characterize, but also very versatile, since the glassy phase both reacts and also goes into solution before the crystalline phase.

The high quantity of amorphous material in the SCSA was found to reduce signals of crystalline material present and this can be confirmed by the increase of intensity of calcite and quartz peaks after the hydrothermal treatment (Figure 2). During the ageing process, the amorphous phase undergoes dissolution in the alkaline media before new crystalline phases are formed and this can be confirmed by the disappearance of the broad diffraction hump that had appeared in SCSA the XRD pattern (Figure 1).

After $24 \mathrm{~h}$ and $45 \mathrm{~h}$ of hydrothermal crystallization, the major zeolitic phase produced was identified as zeolite Na-P1 $\left(\mathrm{Na}_{6} \mathrm{Si}_{10} \mathrm{Al}_{6} \mathrm{O}_{32} \cdot 2 \mathrm{H}_{2} \mathrm{O}\right.$, ICDD/JCPDS 39-0219). Nevertheless, there was still appreciable presence of calcite and quartz that was partially dissolved under these experimental conditions. With reaction time, intensities of zeolite Na-P1 peaks increased indicating that this variation in the synthetic method provides greater dissolution of the $\mathrm{Si}$ and $\mathrm{Al}$ present in the ash as required for the zeolite synthesis. Therefore, synthesis for $45 \mathrm{~h}$ was chosen as the best condition for the hydrothermal treatment process.

Previous studies reported the formation of zeolite-P synthesized from bagasse fly ash $[15,16,17,18]$.

\subsubsection{Chemical Composition}

The chemical composition of sugarcane straw ash (SCSA) and synthesized zeolite (SCSA-45), as well as its loss on ignition, are provided by Table 1 . In sugarcane straw ash, silica is the primary component with small amounts of aluminium, calcium, potassium and iron compounds. When compared with previously published chemical data $[8,9]$, the percentages of the main oxides present in sugarcane straw ash are lower than values found in the cited reference. This could be related to the different calcining temperature used and controlled or uncontrolled calcining temperatures conditions. Furthermore, the silica content is probably related to the soils where sugarcane grows, as well as to other factors, such as fertilization methods and soil management.

Silica is absorbed from the soil through the roots of sugarcane. Accumulated silica between the plant's cuticle and cell walls acts as a physical barrier against the penetration of pathogenic fungi and reduces water loss through transpiration [20].

Loss on ignition (LOI) implied in high weight loss of about $60 \%$, and is mainly attributed to the presence of organic matter in the waste sample. The weight percent of the major oxides in raw SCSA and loss on ignition have changed after zeolite synthesis. There is an increase in $\mathrm{NaO}$ amount in SCSA-45, which is due to entrapment of sodium ions to neutralize the negative charge on aluminosilicate gel [21]. Using the fusion approach some part of the biomass was digested and promoted the increase of most of contents and the decrease of weight loss.
Table 1. Chemical composition of the sugarcane straw ash and synthesized zeolite

\begin{tabular}{|c|c|c|}
\hline \multirow{2}{*}{ Oxides } & \multicolumn{2}{|c|}{$\% \mathrm{wt}$} \\
\hline & SCSA & SCSA-45 \\
\hline $\mathrm{SiO}_{2}$ & 25.3 & 31.6 \\
\hline $\mathrm{Al}_{2} \mathrm{O}_{3}$ & 0.68 & 3.70 \\
\hline $\mathrm{Na}_{2} \mathrm{O}$ & 0.05 & 3.30 \\
\hline $\mathrm{K}_{2} \mathrm{O}$ & 3.78 & 1.15 \\
\hline $\mathrm{CaO}$ & 3.98 & 13.4 \\
\hline $\mathrm{SO}_{3}$ & 0.92 & - \\
\hline $\mathrm{Fe}_{2} \mathrm{O}_{3}$ & 1.19 & 1.55 \\
\hline $\mathrm{MgO}$ & 0.96 & 3.05 \\
\hline $\mathrm{Cl}$ & 0.41 & - \\
\hline $\mathrm{P}_{2} \mathrm{O}_{5}$ & 0.44 & 0.37 \\
\hline $\mathrm{MnO}$ & 0.38 & 0.58 \\
\hline $\mathrm{TiO}_{2}$ & 0.06 & 0.24 \\
\hline $\mathrm{BaO}$ & 0.14 & - \\
\hline $\mathrm{Cr}_{2} \mathrm{O}_{7}$ & 0.08 & - \\
\hline $\mathrm{SrO}_{2}$ & 0.01 & - \\
\hline $\mathrm{NiO}$ & 0.001 & - \\
\hline $\mathrm{ZnO}$ & 0.01 & - \\
\hline loss on ignition & 61.6 & 41.7 \\
\hline
\end{tabular}

\subsubsection{Scanning Electron Microscopic Analysis}

The morphology of the starting material and chosen synthesis product were observed by scanning electron microscopy. SEM micrograph of SCSA (Figure 3) seems like fibrous material containing large shallow pores with strands in each fold. The SCSA before reaction mostly contain noncrystalline glass phase, with a loose structure and possess smooth surface particle because the surface is covered by an aluminosilicate glass phase. SCSA also possesses irregular shapes and surfaces.

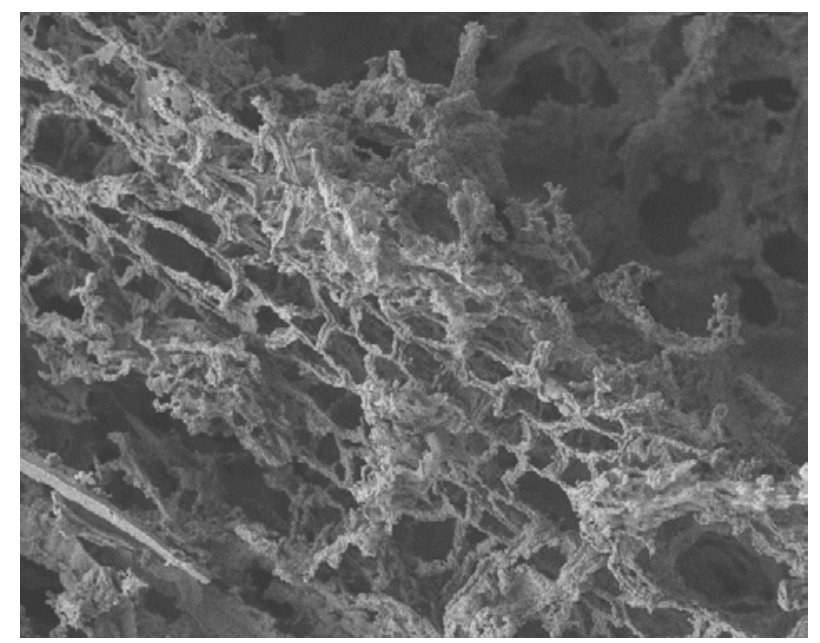

Figure 3. Scanning electron microscope micrographs of SCSA

Figure 4a, the SEM micrographs exhibit the occurrence of particles of irregular shape and smooth surface and agglomeration of particles forming clusters in SCSA-45 as a result of alkaline treatment, which reduces the glass phase as shown in X-ray diffraction patterns (Figure 2). After treatment, the particles of SCSA-45 seem to be more porous due to changes in the surface of the particles, and the formation of NaP1 zeolite with tabular crystals is 
confirmed (Figure 4b). This morphology can be seen also in zeolite NaP1 sample synthesized from coal fly ash $[22,23]$.

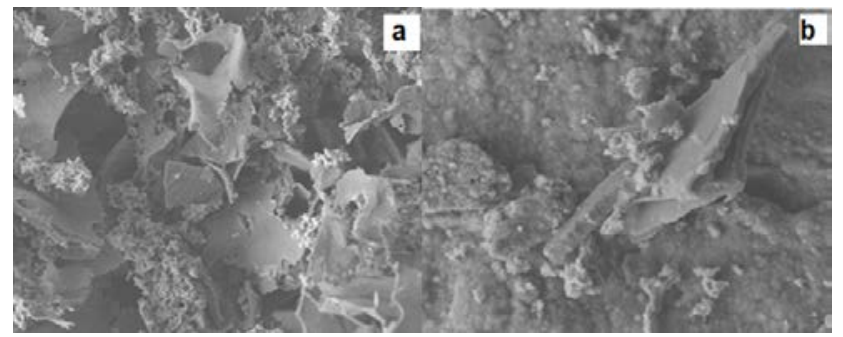

Figure 4. Scanning electron microscope micrographs of SCSA-45

\subsubsection{Particle size Distribution}

Figure 5 and Figure 6 report the absolute and cumulative, respectively, particle size distributions for the sugarcane straw ash (SCSA) and synthesized zeolite (SCSA-45). These distributions specify that the majority of particles (90\%) lie below $69.75 \mu \mathrm{m}$ in case of SCSA-45, while in SCSA majority of particles (90\%) lie below $246.24 \mu \mathrm{m}$. Relevant parameters are again listed in Table 2. The Sauter mean diameter (D [3,2]) was $26.7 \mu \mathrm{m}$ for SCSA and $14.1 \mu \mathrm{m}$ for SCSA-45. The D [3,2] values are indicative of the active surface area of the materials, therefore based on these results it would seem appropriate to consider SCSA-45 as having better adsorption potential than SCSA.

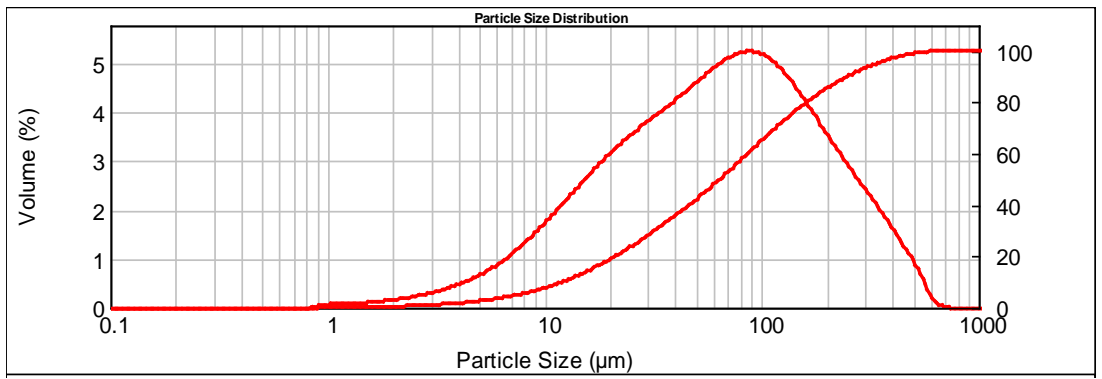

Figure 5. Particle size distribution of the sugarcane straw ash

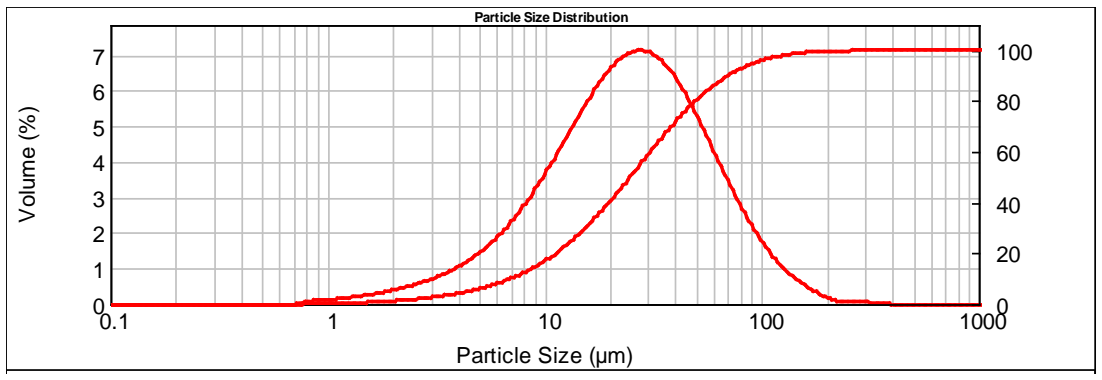

Figure 6. Particle size distribution of the synthesized zeolite

Table 2. Particle size distributions of materials

\begin{tabular}{|c|c|c|c|}
\hline Sample & $\mathrm{D}_{10}(\mu \mathrm{m})$ & $\mathrm{D}_{50}(\mu \mathrm{m})$ & $\mathrm{D}_{90}(\mu \mathrm{m})$ \\
\hline SCSA & 11.293 & 63.888 & 246.665 \\
\hline SCSA-45 & 6.937 & 24.700 & 69.745 \\
\hline
\end{tabular}

\subsubsection{Fourier Transform Infrared Spectroscopy Analysis}

FTIR spectra of SCSA and SCSA-45 are shown in Figure 7. The spectra of the untreated and thermally treated sugarcane straw ashes are very similar. The broad band at about $3430 \mathrm{~cm}^{-1}$ is attributed to the asymmetric and symmetric stretching vibrations $v(\mathrm{O}-\mathrm{H})$, suggesting the presence of amorphous silicate material (glass).

The weak bands at 1622 and $1626 \mathrm{~cm}^{-1}$ are attributed to the bending mode of $\mathrm{H}_{2} \mathrm{O}$ molecules. The bands in the range $3450-1636 \mathrm{~cm}^{-1}$ of the treated products can also be related to the water molecules located inside the channels of zeolite and/or associated with exchangeable cations that is potential to apply for adsorption properties [24].

Bands in the region 453-465 $\mathrm{cm}^{-1}$ are mostly attributed to internal tetrahedron vibrations of Si-O and $\mathrm{Al}-\mathrm{O}$ of the solid residue and zeolite-P. The shifting of the T-O band ( $\mathrm{T}=$ silica or aluminium) at $1082 \mathrm{~cm}^{-1}$ associated with stretching vibrations to lower frequencies $\left(1016 \mathrm{~cm}^{-1}\right)$, indicates zeolitisation of the solid residue. In the zeolite spectra this band is the main asymmetric stretching vibration of the tetrahedral.

The bands at 1450 and $874 \mathrm{~cm}^{-1}$ confirm the formation of zeolite-P. The first can be assigned to a bending mode of the $\mathrm{O}-\mathrm{H}$ bond and the second one to an asymmetric stretching $[25,26]$.

The peaks at $779-796 \mathrm{~cm}^{-1}$ are indicative of quartz and amorphous silica. The lack of absorption bands in the range $3600 \mathrm{~cm}^{-1}-3700 \mathrm{~cm}^{-1}$, characteristic of $\mathrm{Al}-\mathrm{OH}-\mathrm{Al}$ stretching, suggests that discrete, poorly crystalline Alrich phases are not present.

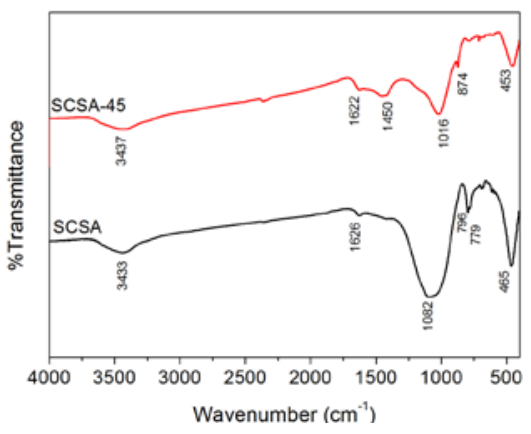

Figure 7. FTIR spectra of SCSA and SCSA-45 


\subsubsection{Thermal Properties}

Figure 8 shows TG-DSC curves of SCSA-45. Thermal behaviours of the zeolitic material from sugarcane straw ash is characterized by the existence of five stages which can be identified both by the TG and DSC curves. The first mass lost step corresponds to the liberation of physically adsorbed water in function of an endothermic event until $101^{\circ} \mathrm{C}$.

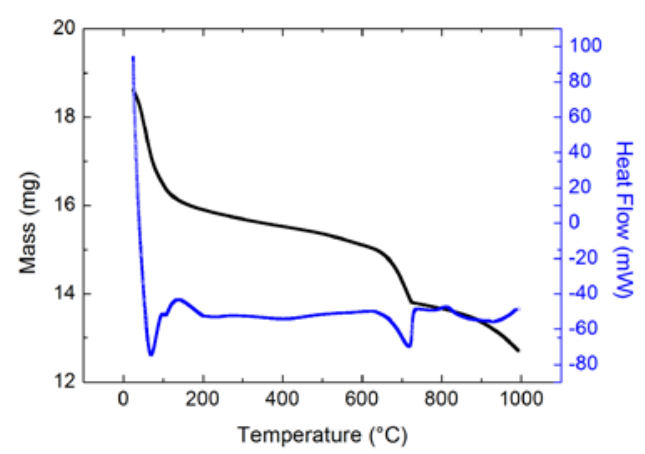

Figure 8. Thermoanalytical curves for zeolitic material from sugarcane straw ash

An exothermic peak between $124-200^{\circ} \mathrm{C}$ shown a possibility of loss inner water probably associated to a crystalline transition. Between $200-400^{\circ} \mathrm{C}$ there are a $3^{\text {rd }}$ thermal decomposition with transformation of $\mathrm{MgCO}_{3}$ producing $\mathrm{MgO}$ and $\mathrm{CO}_{2}$ (1.76 and $1.923 \%$, respectively). These small amounts were not observed in XRD may due loss concentrations. Losses between $400-600^{\circ} \mathrm{C}$ show $4^{\text {th }}$ thermal decomposition step. It is possible to estimate a decomposition of $\mathrm{Na}_{2} \mathrm{CO}_{3}$ in $\mathrm{Na}_{2} \mathrm{O}$ and $\mathrm{CO}_{2}$ (3.39\% and $2.40 \%)$. Calcite thermal decomposition occurs in $5^{\text {th }}$ decomposition step, between $600-850^{\circ} \mathrm{C}$ with and endothermic event producing $\mathrm{CaO}$ and $\mathrm{CO}_{2}(8.84 \%$ and $6.929 \%)$.

\subsection{7. $\mathrm{N}_{2}$ Adsorption and Surface Area (BET)}

Nitrogen adsorption isotherm of zeolitic material from sugarcane straw ash is shown in the Figure 9. According to the IUPAC classification isotherms are of type IV with a hysteresis loop which is associated with mesoporous materials (6.13nm). Sample exhibit a highly degree of structural ordering as inferred from steepness of the capillary condensation step on the adsorption isotherm, can be noted H3 hysteresis that indicate shape porous in wedge, cones or parallel plates [27].

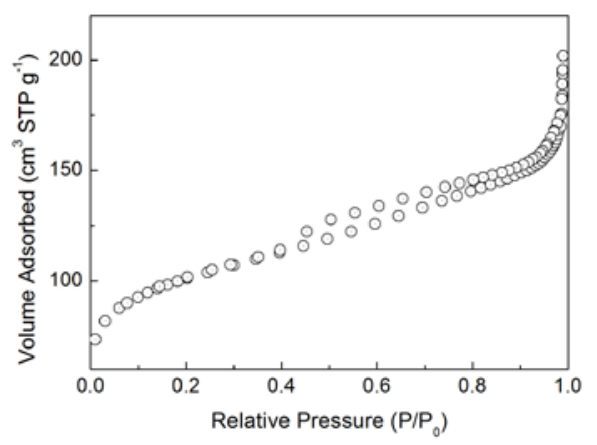

Figure 9. $\mathrm{N}_{2}$ adsorption-desorption isotherm of zeolitic material from sugarcane straw ash
Table 3 shows results from a nitrogen adsorption study including the BET surface areas, pore volumes, and average pore diameters of SCSA-45. It is obvious from Table 3 that zeolitic material from sugarcane straw ash has high specific surface area $\left(350.13 \mathrm{~m}^{2} \mathrm{~g}^{-1}\right)$. Their average pore size is $6.13 \mathrm{~nm}$ determined by $\mathrm{BJH}$ calculation (Barret-Joymer-Halnda method), which was in the mesopore range (pore size, 2-50nm). The mesoporous structure of the synthesized adsorbent is due the decrease in average adsorption pore diameter and average desorption pore diameter after hydrothermal treatment of sugarcane straw ash. Similar results were also obtained for the synthesis of zeolites from bagasse fly ash $[15,16,17]$.

Table 3. Textural properties of synthesized SCSA-45

\begin{tabular}{|c|c|}
\hline Textural Properties & Obtained values \\
\hline BET surfasse area $\left(\mathrm{m}^{2} \mathrm{~g}^{-1}\right)$ & 350.13 \\
\hline Langmuir surface $a r e a\left(\mathrm{~m}^{2} \mathrm{~g}^{-1}\right)$ & 470.57 \\
\hline Micropore area $\left(\mathrm{m}^{2} \mathrm{~g}^{-1}\right)$ & 173.11 \\
\hline Micropore volume $\left(\mathrm{cm}^{2} \mathrm{~g}^{-1}\right)$ & 0.08 \\
\hline Adsorption average pore diameter $($ by BET $)(\mathrm{nm})$ & 2.99 \\
\hline Desorption average pore diameter (by BET) $(\mathrm{nm})$ & 3.09 \\
\hline BJH Adsorption average pore diameter $(\mathrm{nm})$ & 6.13 \\
\hline BJH Desorption average pore diameter $(\mathrm{nm})$ & 5.71 \\
\hline
\end{tabular}

\subsubsection{Application for Removal of Crystal Violet Dye}

The capacity of zeolitic material from sugarcane straw ash to remove $\mathrm{CV}$ from aqueous solutions was tested at various dye concentrations. The adsorption capacity and percentages are shown in Table 4. According to Table 4, the SCSA-45 was found to successfully remove CV from aqueous solution at high concentrations with adsorption percentage ranged from $99.7 \%$ to $100 \%$. The maximum loading capacity in the range concentration studied was $93.5 \mathrm{mg} \mathrm{g}^{-1}$.

Table 4. Amounts and percentages of CV adsorbed onto SCSA-45 as function of initial concentration

\begin{tabular}{|c|c|c|}
\hline $\mathrm{C}_{\mathrm{o}}\left(\mathrm{mg} \mathrm{L}^{-1}\right)$ & $\mathrm{q}\left(\mathrm{mg} \mathrm{g}^{-1}\right)$ & Removal (\%) \\
\hline 45 & 4.42 & 100 \\
\hline 100 & 10.4 & 100 \\
\hline 160 & 16.0 & 100 \\
\hline 200 & 20.8 & 100 \\
\hline 236 & 23.5 & 99.8 \\
\hline 300 & 28.4 & 99.7 \\
\hline 940 & 93.5 & 99.7 \\
\hline
\end{tabular}

\section{Conclusion}

The sugar cane straw ash (SCSA) was effectively converted into the zeolitic material by alkali fusion followed by hydrothermal treatment. The formation of the zeolite-P as major constituent was confirmed by XRD and FTIR. The TG/DSC and SEM data are in good agreement with development of different crystalline phases in SCSA after treatment. The zeolitic material from sugarcane straw ash can be utilized as low-cost adsorbents for removal of crystal violet from aqueous system. The use of the sugarcane straw ash for production of zeolite appears as an alternative and environmental friendly use of this material, once it is an agricultural residue, that doesn't have another important use. 


\section{Acknowledgement}

The authors are grateful to Counselor National de Desenvolvimento Científico e Technologic (CNPq) for financial support.

\section{References}

[1] ÚNICA (2011) - União da Indústria de Cana-De-Açúcar. Available: http://www.unica.com.br/. [Accessed Dec.18, 2013].

[2] Costa, S.M., Mazzola, P.G., Silva, J.C.A.R., Pahl, R, Pessoa, A. and Costa, S.A., "Use of sugarcane Straw as a source of cellulose for textile fiber production,” Industrial Crops and Products, 42. 189-194. 2013.

[3] Saad, M.B.W., Oliveira, L.R.M., Cândido, R.G., Quintana, G., Rocha, G.J.M. and Gonçalves, A.R., "Preliminary studies on fungal treatment of sugarcane straw for organosolv pulping," Enzyme and Microbial Technology, 43. 220-225. 2008.

[4] Moriya, R.Y., Gonçalves, A.R. and Duarte, M.C., "Ethanol/water pulps from sugar cane straw and their biobleaching with xylanase from Bacillus pumilus,” Applied Biochemistry and Biotechnology, 137-140. 501-513. 2007.

[5] Cançado, J.E., Saldiva, P.H., Pereira, L.A., Lara, L.B., Artaxo, P., Martinelli, L.A., Arbex, M.A., Zanobetti, A. and Braga, A.L., "The Impact of Sugar Cane-Burning Emissions on the Respiratory System of Children and the Elderly," Environmental Health Perspectives, 114. 725-729. 2006.

[6] Ribeiro, H., "Sugar cane burning in Brazil: respiratory health effects,” Revista de Saúde Pública, 42. 370-376. 2008.

[7] Andrade, S.J., Cristale, J., Soares, S.F.S., Zocolo, G.J. and Marchi, M.R.R., "Contribution of sugar-cane harvesting season to atmospheric contamination by polycyclic aromatic hydrocarbons (PAHs) in Araraquara city, such showed Southeast Brazil," Atmospheric Environment, 44. 2913-2919. 2010.

[8] Hernandez, J.F.M, Middendorf, B., Gehrke, M. and Budelmaun, H., "Use of wastes of the sugar industry as pozzolana in lime pozzolana binders: Study of the reaction," Cement and Concrete Research, 28. 1528-1536. 199.

[9] Frias, M., Villar-Cociña, E. and Valencia-Morales, E., "Characterisation of sugar cane straw waste as pozzolanic material for construction: calcining temperature and kinetic parameters," Waste Management, 27. 533-538. 2007.

[10] Morales, E.V., Villar -Cociña, E., Frías, M., Santos, S. F. and Savastano Jr., H., "Effects of calcining conditions on the microstructure of sugar cane waste ashes (SCWA): Influence in the pozzolanic activation," Cement and Concrete Composites, 31. 22-28. 2009.

[11] Izidoro, J.C., Fungaro, D.A., Santos, F.S. and Wang, S., "Characteristics of Brazilian coal fly ashes and their synthesized zeolites," Fuel Processing Technology, 97. 38-44. 2012.

[12] Fungaro, D.A., Borrely S.I. and Carvalho, T.E.M., "Surfactant Modified Zeolite from Cyclone Ash as Adsorbent for Removal of
Reactive Orange 16 from Aqueous Solution,” American Journal of Environmental Protection, 1. 1-9. 2013.

[13] Yamaura, M. and Fungaro, D.A., "Synthesis and characterization of magnetic adsorbent prepared by magnetite nanoparticles and zeolite from coal fly ash,” Journal of Materials Science, 48. 50935101. 2013.

[14] Izidoro J.C., Fungaro, D.A., Abbott, J.E. and Wang, S., "Synthesis of zeolites $\mathrm{X}$ and $\mathrm{A}$ from fly ashes for cadmium and zinc removal from aqueous solutions in single and binary ion systems," Fuel, 103. 827-834. 2013.

[15] Shah, B., Tailor, R.and Shah, A., "Adaptation of bagasse fly ash, a sugar industry solid waste into zeolitic material for the uptake of phenol," Environmental Progress \& Sustainable Energy, 30. 358367, 2011.

[16] Shah, B., Tailor, R. and Shah, A., "Sorptive sequestration of 2chlorophenol by zeolitic materials derived from bagasse fly ash," Journal of Chemical Technology and Biotechnology, 86. 12651275. 2011

[17] Shah, B., Tailor, R. and Shah, A., "Zeolitic bagasse fly ash as a low-cost sorbent for the sequestration of p-nitrophenol: equilibrium, kinetics, and column studies,” Environmental Science and Pollution Research International, 19. 1171-86. 2012.

[18] Worathanakul, P., Kittipalarak, S. and Anusarn, K., "Utilization Biomass from Bagasse Ash for Phillipsite Zeolite Synthesis," Advanced Materials Research, 383-390. 4038-4042. 2011.

[19] Kruk, M., Jaroniec, M. and Sayari, A, “Application of large pore MCM-41 molecular sieves to improve pore size analysis using nitrogen adsorption measurements," Langmuir, 13. 6267-6273. 1997.

[20] Barboza Filho, M.P. and Prabhu, A.S., Aplicação de silicato de cálcio na cultura do arroz (Application of calcium silicate in rice culture) - Circular Técnica 51, EMBRAPA. Santo Antônio de Goiás, 2002. (in portuguese).

[21] Murayama, N., Yamamoto, H. and Shibata, "Mechanism of zeolite synthesis from coal fly ash by alkali hydrothermal reaction," International Journal of Mineral Processing, 64. 1-17. 2002.

[22] Derkowski, A. and Michalik, M., "Statistical approach to the transformation of fly ash into zeolites," Mineralogia Polonica, 38. 47-69. 2007.

[23] Moutsatsou, A., Stamatakis, E., Hatzitzotzia, K. and Protontarios, V., "The utilization of Ca-rich and Ca-Si-rich fly ashes in zeolites production,” Fuel, 85: 657-663, 2006.

[24] Mouhtaris, T., Charistos, D., Kantiranis, N., Filippidis, A., KassoliFournaraki, A. and Tsirambidis, A., "GIS-type zeolite synthesis from Greek lignite sulphocalcic fly ashes promoted by NaOH solutions," Microporous and Mesoporous Material, 61, 5767. 2003.

[25] Vadapalli, V.R.K., Gitari, W.M., Ellendt, A., Petrik, L.F. and Balfour, G., "Synthesis of zeolite-p from coal fly ash derivative and its utilisation in mine-water remediation," South African Journal of Science, 106. 1-7. 2010.

[26] Atun, G., Hisarliet, G., Kurtoglu, A.E. and Ayar, N., "A comparison of basic dye adsorption onto zeolitic materials synthesized from fly ash,” Journal of Hazardous Materials, 187. 562-573. 2011.

[27] Figueiredo, J.L. and Ramôa Ribeiro, F., Catálise Heterogênea. Fundação Calouste Gulbenkian, Lisboa, 1989. 